\title{
DNA methyltransferase inhibitor 5-azacytidine in high dose promotes ultrastructural maturation of cardiomyocyte
}

\author{
Mona Saheli ${ }^{1}$, Vahid Pirhajati Mahabadi ${ }^{2,3}$, Seyed Alireza Mesbah-Namin ${ }^{4}$, Alexander Seifalian ${ }^{5}$, \\ Zahra Bagheri-Hosseinabadi ${ }^{6,7}$
}

${ }^{1}$ Department of Anatomical Sciences, Faculty of Medicine, Kerman University of Medical Sciences, Kerman, Iran; ${ }^{2}$ Neuroscience Research Center, Vice-Chancellor for Research and Technology, Iran University of Medical Sciences, Tehran, Iran; ${ }^{3}$ Cellular and Molecular Research Center, ViceChancellor for Research and Technology, Iran university of Medical Sciences, Tehran, Iran; ${ }^{4}$ Department of Clinical Biochemistry, Faculty of Medical Sciences, Tarbiat Modares University, Tehran, Iran; ${ }^{5}$ Nanotechnology and Regenerative Medicine Commercialisation Centre (NanoRegMed Ltd.), London BioScience Innovation Centre, London, UK; ${ }^{6}$ Department of Clinical Biochemistry, School of Medicine, Rafsanjan University of Medical Sciences, Rafsanjan, Iran; ${ }^{7}$ Physiology Research Center, Kerman University of Medical Sciences, Kerman, Iran

Contributions: (I) Conception and design: Z Bagheri-Hosseinabadi, SA Mesbah-Namin; (II) Administrative support: V Pirhajati Mahabadi, M Saheli; (III) Provision of study materials or patients: Z Bagheri-Hosseinabadi; (IV) Collection and assembly of data: Z Bagheri-Hosseinabadi, M Saheli; (V) Data analysis and interpretation: Z Bagheri-Hosseinabadi, M Saheli; (VI) Manuscript writing: All authors; (VII) Final approval of manuscript: All authors.

Correspondence to: Zahra Bagheri-Hosseinabadi. Department of Clinical Biochemistry, School of Medicine, Rafsanjan University of Medical Sciences, Rafsanjan, Iran; Physiology Research Center, Kerman University of Medical Sciences, Kerman, Iran. Email: Baghery.zahra@yahoo.com.

Background: The adult human heart muscle cells, cardiomyocytes are not capable of regenerate after injury. Stem cells are a powerful means for future regenerative medicine because of their capacity for selfrenewal and multipotency. Several studies have reported the cardiogenic potential in human adipose tissuederived stem cells (ADSCs) differentiation, but there is still no efficient protocol for the induction of cardiac differentiation by 5 -azacytidine (5-Aza). The present study involves characterization and mainly, the ultrastructure of ADSCs derived cardiomyocyte-like cells.

Methods: The cultured ADSCs were treated with $50 \mu \mathrm{M}$ 5-Aza for 24 hours, followed by a 10-week extension. At different time points, cardiomyocyte-like cells were assessed by qRT-PCR and were evaluated by transmission electron microscopy at $10^{\text {th }}$ week.

Results: The expression of cardiac-specific markers entailing cardiac troponin I (cTnI), connexin 43, myosin light chain-2v (Mlc-2v), increased over 10 weeks and the highest expression was at $10^{\text {th }}$ week. The expression of the $\beta$-myosin heavy chain ( $\beta-M H C$ ) increased significantly over 5 weeks and then decreased. At the ultrastructural level myofibrils, transverse tubules (T-tubules), sarcoplasmic reticular membrane, and intercalated discs were present.

Conclusions: These data suggest that treatment with 5-Aza in high dose could promote differentiation of ADSCs into cardiomyocyte-like cells. These differentiated cells could be used for regeneration of damaged cardiomyocytes with the $3 \mathrm{D}$ scaffold for delivery of the cells.

Keywords: Adipose tissue-derived stem cells (ADSCs); cardiomyocyte; 5-azacytidine (5-Aza); regenerative medicine; tissue engineering

Received: 08 February 2020; Accepted: 01 December 2020; Published: 15 December 2020.

doi: 10.21037/sci-2020-007

View this article at: http://dx.doi.org/10.21037/sci-2020-007 


\section{Introduction}

According to WHO reports, cardiovascular diseases (CVDs) are one of the major causes of death globally. This is $31 \%$ of all global deaths. Despite advances in pharmacological and surgical interventions, following ischemic cascade result in cell apoptosis and extensive loss of cardiomyocytes. Due to the proliferation capacity of cardiomyocytes is highly limited, so the loss of cardiomyocytes follows fibrosis and formation of non-contractile scar tissue and heart failure $(1,2)$. Currently, cardiac transplantation is the only definitive treatment in patients with end-stage heart failure, however, it is limited by organ donor shortage and high risk of immune rejection $(3,4)$.

Cell therapy has been proposed as an alternative method to restore damaged heart tissue. Stem cells possess a remarkable regenerative potential and many studies suggest stem cells as an available alternative approach for the treatment of damaged heart (5-7). Embryonic stem cells (ESCs) and adult stem cells (ASCs) have been used for cell therapy procedures, but ESCs have some limitations such as teratoma formation and ethical considerations (8-10). ASCs, have been successfully isolated from various sources and they have multi-lineage differentiation potential. Among all ASCs sources, adipose tissue-derived stem cells (ADSCs) are the most established and potent source for ASCs. This has been due to ease of isolation, therefore has been used all over the world for the treatment of various diseases, including cardiovascular (11-13).

Although the differentiation capacity of the ADSCs is well known; the differentiation efficiency is variable and depending on the inducer and protocol used. ADSCs could be differentiated into cardiomyocytes by means of different inducers such as 5-azacytidine (5-Aza), DMSO, and oxytocin. However, 5-Aza is the most usual cardiac inducer that would be used until now (10,14-16). 5-Aza which is a pyrimidine nucleoside analogue of cytidine along with DNA demethylation commences various cell differentiation programs. Dynamic DNA methylation affected cardiomyocyte development and maturation, in addition to 5-Aza is an impressive DNA methyltransferase inhibitor, which is extensively used in demethylation treatment to cardiomyocyte like differentiation $(17,18)$. Although inefficiency of 5-Aza for cardiogenic differentiation of ADSCs was reported by several researchers $(10,19)$.

To increase the efficacy of cardiomyocyte differentiation, ultrastructural aspects of mesenchymal stem cell-derived cardiomyocyte-like cells should be investigated and included as an important parameter. We hypothesized that prolonged maintenance of ADSCs in culture after 5-Aza could improve their differentiation potentiality. Therefore, this study aimed to evaluate the in vitro potential differentiation of ADSCs into cardiomyocyte over 10 weeks through cardiac gene expression and ultrastructural features. We present the following article in accordance with the MDAR reporting checklist (available at http:// dx.doi.org/10.21037/sci-2020-007).

\section{Methods}

\section{ADSCs isolation and culture}

Three healthy women, ages $40 \pm 3$ years, underwent elective liposuction procedure in a hospital in order to collect adipose tissue samples. The study was conducted in accordance with the Declaration of Helsinki (as revised in 2013). The study was approved by the ethics board of Kerman University of Medical Sciences, with approval number: IR.KMU.REC.1394.639. Written consents were obtained prior to this course of action. The cells were isolated according to previously published protocol with slight modification (20). Samples were washed with PBS containing antibiotics. After that samples were cut into small pieces and were incubated in culture media with $0.5 \mathrm{mg} / \mathrm{mL}$ collagenase type $\mathrm{IV}$, they were shaken intermittently at $37^{\circ} \mathrm{C}$ for 1 hour. After centrifugation cell pellet was cultured in DMEM/F12 supplemented with $10 \%$ (V/V) FBS, penicillin $(100 \mathrm{U} / \mathrm{mL})$, streptomycin $(100 \mathrm{U} / \mathrm{mL})$ and amphotericin-B $(2.5 \mu \mathrm{g} / \mathrm{mL})$ and the medium was changed twice weekly until the cells reached $80 \%$ confluence. Immunophenotyping of cultured ADSCs was assessed by flow cytometry and multilineage differentiation of MSCs was evaluated by Induction of adipogenic, osteogenic and chondrogenic differentiation as previously reported (21).

\section{Induction of cardiomyogenic differentiation}

For cardiac differentiation, $1 \times 10^{4}$ cells $/ \mathrm{cm}^{2}$ ADSCs at $4^{\text {th }}$ passage were seeded per well in 6 well plates. The following day, the cells were incubated in the cardiogenic medium containing DMEM/F12, penicillin $(100 \mathrm{U} / \mathrm{mL})$, streptomycin $(100 \mathrm{U} / \mathrm{mL})$, amphotericin-B $(2.5 \mu \mathrm{g} / \mathrm{mL})$ and $50 \mu \mathrm{M} 5$-Aza for $24 \mathrm{~h}$, then the medium replaced with noninductive medium over 10 weeks. 
Table 1 Sequence specific primers for quantitative real-time PCR (qRT-PCR)

\begin{tabular}{lll}
\hline Gene & Forward sequence $\left(5^{\prime}-3^{\prime}\right)$ & Reverse sequence $\left(5^{\prime}-3^{\prime}\right)$ \\
\hline$c T n l$ & CAAGCAGGTGAAGAGGAGG & CTCAAACTTTTCTTGCGGC \\
$C \times 43$ & CTCAACTGCTGGAGGGAAGG & CCAGAAGCGCACATGAGAGA \\
$\beta-M H C$ & GATCACCAACAACCCCTACG & ATGCAGAGCTGCTCAAAGCA \\
$M L C 2 v$ & AAAGAGGCTCCAGGTCCAAT & CCTCTCTGCTTGTGTGGTCA \\
GAPDH & TGCACCACCAACTGCTTAGC & GGCATGGACTGTGGTCATGA \\
\hline
\end{tabular}

cTnl, cardiac troponin I; Cx43, connexin 43; $\beta$-MHC, $\beta$-myosin heavy chain; Mlc2v, myosin light chain-2v.

\section{Relative quantitative PCR (qPCR) for cardiac-specific genes}

The experiment to extract the total RNA from the treated ADSCs using a precipitation method by means of RNX total RNA isolation Kit (CinnaGen, Tehran, Iran) was performed 1,5 , and 10 weeks after the beginning of experiments, as stated in the manufacturer's manual. Agarose gel electrophoresis was used to evaluation of quantity and quality of total RNA extracts. Then firststrand cDNA synthesis kit (Revert Aid cDNA synthesis kit, Thermo scientific, USA) was used in order to perform reverse transcription. After cDNA synthesis, expression of target genes including connexin 43 , cardiac troponin I (cTnI), MLC2v and $\beta$-myosin heavy chain ( $\beta-M H C)$ using specific primers (Table 1) was performed using the Maxima SYBR Green Master Mix (Thermo Fisher) in a thermal cycler (Corbett Research, Inc., Sydney, Australia). Relative expression of the sample gene was evaluated by $2^{-\Delta \Delta \mathrm{Ct}}$ method and was normalized to GAPDH as the internal control (22).

\section{Transmission electron microscopy (TEM)}

At the end of the $10^{\text {th }}$ week, the cell pellets were washed with PBS and fixed in $2.5 \%$ glutaraldehyde in $0.1 \mathrm{M}$ phosphate buffer $\left(\mathrm{pH} \mathrm{7.4)}\right.$ at $4{ }^{\circ} \mathrm{C}$ for $24 \mathrm{~h}$ and then washed with $1 \mathrm{~mL}$ of phosphate buffer. Then, cells were post-fixed in $1 \%$ buffered osmium tetroxide for $2 \mathrm{~h}$ and washed with distilled water. The cells were dehydrated in graded series of alcohol, cleared in acetone and embedded in epoxy resin. Ultrathin sections were prepared by an ultramicrotome and placed on copper grids, then stained with uranyl acetate. Sections were observed under a Zeiss EM 900 TEM (Germany) at $80 \mathrm{kV}$ voltage.

\section{Statistical analysis}

Our results were presented as mean \pm standard deviation (SD), and data analysis was performed using SPSS 16 software package. The groups were compared by one-way analysis of variance (ANOVA) with post hoc correction. The difference between groups was considered as statistically reliable at $\mathrm{P} \leq 0.05$.

\section{Results}

\section{Expression of cardiac-specific genes during 10 weeks}

To evaluation cardiac differentiation of ADSCs, gene expression profile was quantified 1,5 , and 10 weeks after cell induction. We used untreated mesenchymal stem cells 2 days after seeding as a control group. Expression of maturation markers such as connexin 43 and MLC2 $v$ significantly upregulate after first as well as $5^{\text {th }}$ and $10^{\text {th }}$ weeks compare to control group. Expression of cTnI revealed an incremental increase and the highest expression was shown in the $10^{\text {th }}$ week. Whereas expression of $\beta-$ MHC significantly upregulated after the first week as well as the $5^{\text {th }}$ weeks and then significantly downregulated at $10^{\text {th }}$ week. Consequently, the results of qRT-PCR showed that the rate of expression of cTnI (approximately 10 folds), connexin 43 (approximately 4 folds) and MLC2v (approximately 4 folds) at week $10^{\text {th }}$ increased compared to the first week (Figure 1).

Our data showed prolong maintenance of the cells after exposure with a high dose of 5-Aza can promote cardiac genes expression.

\section{Ultrastructural analysis of differentiated ADSCs}

At 10 weeks after cell induction with 5-Aza cytidine, cells and their nuclei were elongated. Dense nuclei which 
cTNI
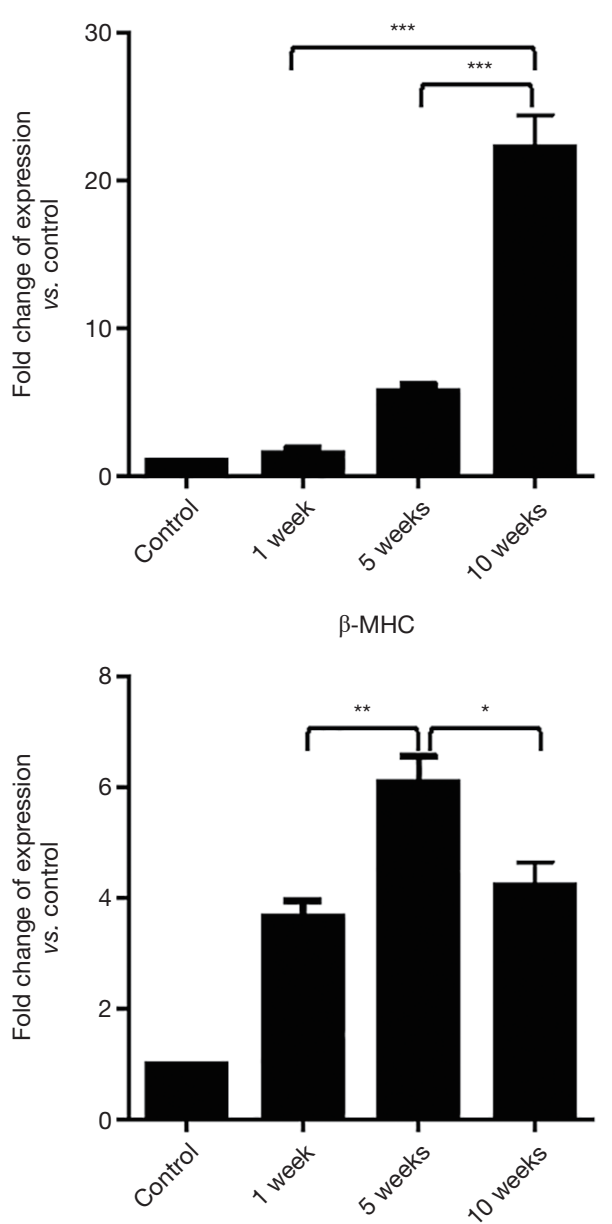

Cx43

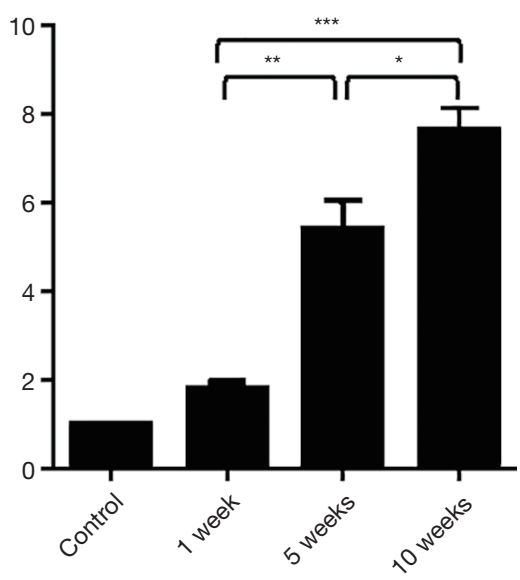

MLC2v

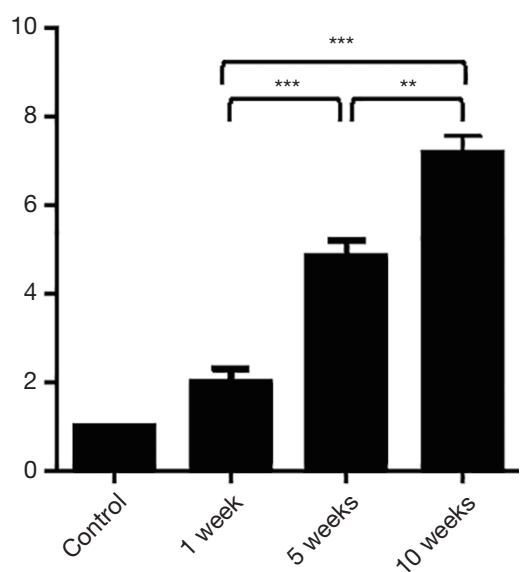

Figure 1 Gene expression in cardiomyocyte-like cells. All gene expression fold changes are relative to the expressions of ADSCs with normalization to GAPDH expression by the $2^{-\Delta \Delta c t}$ method. ( $\mathrm{n}=3$, *, $\mathrm{P}<0.05$; **, $\mathrm{P}<0.01$, and *** $\mathrm{P}<0.001$ ). cTnI, cardiac troponin I; Cx43, connexin 43; $\beta$-MHC, $\beta$-myosin heavy chain; Mlc2v, myosin light chain-2v; ADSCs, adipose tissue-derived stem cells.

contain some heterochromatic regions were observed in the differentiated cells. Myofibrils which oriented primarily parallel to the longitudinal axis of the cells were used to fill cell cytoplasm. Densely packed mitochondria were determined in close association with the myofibrils. In particular, the sarcolemma of cells developed tubular invaginations and made transverse tubules (T-tubules) that penetrated between myofibrils in the cytoplasm. Differentiated cells showed abundant sarcoplasmic reticular membrane, and intercalated discs (mixed type junction) with adherents, gap, and desmosome junctions (Figure 2).

\section{Discussion}

The possibility of using stem cells as an alternative treatment in end-stage CVDs has opened up new prospects in regenerative medicine. But transplantation of pre-primed stem cells suggested better regenerative potential than untreated stem cells in CVD treatment $(23,24)$. Recent studies reported that ADSCs could differentiate into cardiomyocyte-like cells if optimized culture conditions were provided (25). Many previous studies have proved the effects of DNA methyltransferase inhibitor 5-Aza on cardiomyocyte differentiation $(17,26,27)$. Although there are several studies showed the differentiation, efficient generation of cardiomyocyte-like cells by using 5-Aza has not been established and the main challenges are to find an effective method in which the cells can be differentiated at a very high efficacy. Reports have implied increasing 5-Aza dose and exposure time of mesenchymal stem cells that may 

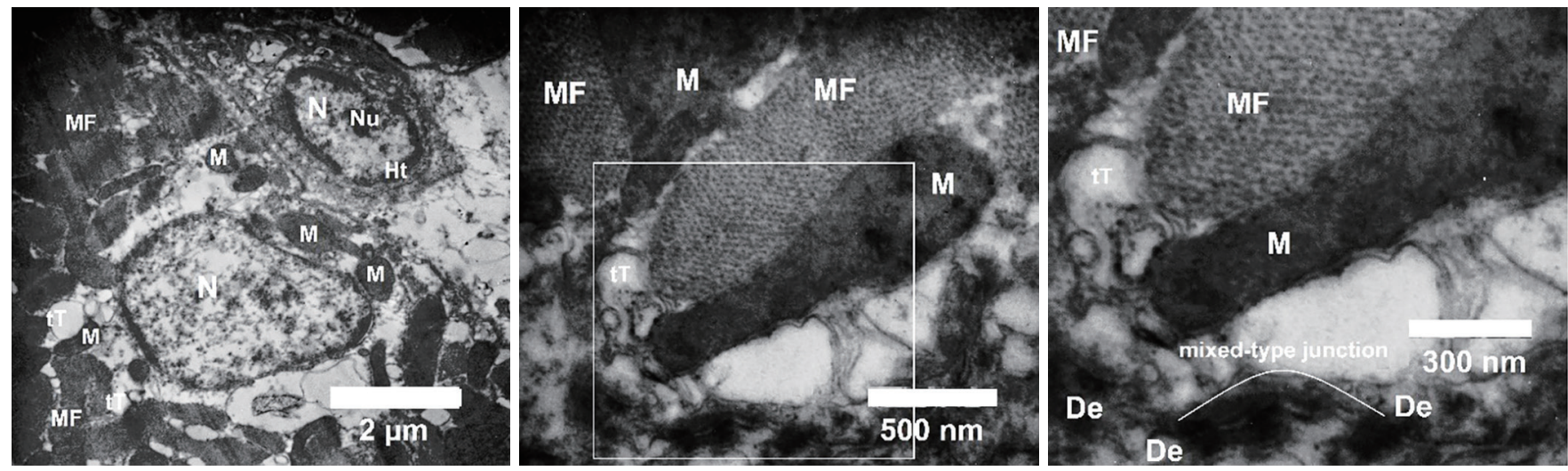

Figure 2 Ultrastructural analysis of cardiomyocyte-like cells. Myofibrils (MF) oriented primarily parallel to the longitudinal axis of the cells, numerous mitochondria $(\mathrm{M})$, T-tubules $(\mathrm{t} \mathrm{T})$, intercalated discs in mixed-type junction were observed. $\mathrm{N}$, nucleus; $\mathrm{Nu}$, nucleolus; Ht, heterochromatin; De, desmosome.

improve the efficacy of differentiated cells $(6,28,29)$. The goal of this study was to present the protocol to generate efficient cardiomyocyte like cells with typical ultrastructural characters.

This study used freshly isolated ADSCs, that previous reports suggested being a suitable choice for stem cell therapy in CVDs (10). These cells were placed under 5-Aza induction. 5-Aza has been used in different dosages to cardiogenic differentiation and many studies reported high dose use of 5-Aza, e.g., $50 \mu \mathrm{M}$ was more effective than low dose such as $3 \mu \mathrm{M}$ (28). Since continuous exposure of high-dose treatment might lead to dramatic cell death, we used $50 \mu \mathrm{M} 5$-Aza for $24 \mathrm{~h}$ and the treated ADSCs were maintained over 10 weeks. Then the expression of cardiac-specific genes like connexin 43, cTnI, MLC2v and $\beta-M H C$ were evaluated at the first, $5^{\text {th }}$ and $10^{\text {th }}$ weeks after induction. Recent studies suggested that 5-Aza increased functional and structural gene expression in differentiated cells $(6,10,28)$. Our findings showed that the pattern of connexin 43, cTnI, MLC2 $\mathrm{v}$ genes expression was in a timedependent manner and increased incrementally from the first to the $10^{\text {th }}$ weeks after induction, but the expression of $\beta-M H C$ increased at first and $5^{\text {th }}$ weeks compare to control group and then decreased at $10^{\text {th }}$ week.

Since the highest gene expression was observed at week 10, therefore, ultrastructural features of differentiated ADSCs were assessed at the same time. Our ultrastructural results revealed matured ultrastructural cardiomyocyte like cells; there were large, elongated cells with condensed heterochromatin ovoid nuclei; also, some mitochondria and sarcoplasmic reticulum was observed in the cytoplasm. The existence of parallel arrays of myofibrils could be defined as an organization of the contractile structures. Additionally, we found the T-tubular system and a specific junctional structure of cardiomyocytes such as fascia adherences, desmosomes and gap junctions. This ultrastructure would be reported by previous studies; Piryaei et al. reported the myofibrillar organization, the formation of T-tubules and intercalated discs after 8 weeks of induction with 5-Aza (6). On the other hand, Rachel et al. showed morphology and structure of differentiated cells would improve by an increase in 5-Aza dose (29).

These results suggest that 5-Aza at a dose of $50 \mu \mathrm{M}$ for $24 \mathrm{~h}$ is an efficient inducer for cardiac differentiation of ADSCs. However, differentiated cells in this study did not have a beating, so the cells were not mature enough like in vivo cardiomyocytes.

In summary, the proposed new protocol demonstrated a positive outcome for cardiomyocyte differentiation by 5-Aza cytidine. The data showed that differentiated cells can express cardiac-specific genes and these cells have mature ultrastructural features. Although further studies are required to gain functional differentiated cells. The proposed in vitro culture system for the generation of cardiomyocyte-like cells has several potential applications in CVDs, including regeneration of cardiac muscle cells.

\section{Acknowledgments}

We would like to thank Dr. Zahra Ramezani in the electron microscopy laboratory of Shahid Beheshti University. Funding: This work was supported by both Modares 
University (grant number: 91-20-33-2003) and Kerman University of Medical Sciences (research plan number: 1729).

\section{Footnote}

Reporting Checklist: The authors have completed the MDAR reporting checklist. Available at http://dx.doi.org/10.21037/ sci-2020-007

Conflicts of Interest: All authors have completed the ICMJE uniform disclosure form (available at http://dx.doi. org/10.21037/sci-2020-007). The authors have no conflicts of interest to declare.

Ethical Statement: The authors are accountable for all aspects of the work in ensuring that questions related to the accuracy or integrity of any part of the work are appropriately investigated and resolved. The study was conducted in accordance with the Declaration of Helsinki (as revised in 2013). The study was approved by the ethics board of Kerman University of Medical Sciences, with approval number: IR.KMU.REC.1394.639. Written consents were obtained prior to this course of action.

Open Access Statement: This is an Open Access article distributed in accordance with the Creative Commons Attribution-NonCommercial-NoDerivs 4.0 International License (CC BY-NC-ND 4.0), which permits the noncommercial replication and distribution of the article with the strict proviso that no changes or edits are made and the original work is properly cited (including links to both the formal publication through the relevant DOI and the license). See: https://creativecommons.org/licenses/by-nc-nd/4.0/.

\section{References}

1. Ng WH, Yong YK, Ramasamy R, et al. Human Wharton's Jelly-Derived Mesenchymal Stem Cells Minimally Improve the Growth Kinetics and Cardiomyocyte Differentiation of Aged Murine Cardiac c-kit Cells in In Vitro without Rejuvenating Effect. Int J Mol Sci 2019;20:5519.

2. Jia Y, Chang Y, Guo Z, Li H. Transcription factor Tbx5 promotes cardiomyogenic differentiation of cardiac fibroblasts treated with 5-azacytidine. J Cell Biochem 2019;120:16503-15.

3. Welp H, Spieker T, Erren M, et al. Sex mismatch in heart transplantation is associated with increased number of severe rejection episodes and shorter long-term survival. Transplant Proc 2009;41:2579-84.

4. Kilic A, Emani S, Sai-Sudhakar CB, et al. Donor selection in heart transplantation. J Thorac Dis 2014;6:1097-104.

5. Baghalishahi M, Efthekhar-Vaghefi SH, Piryaei A, et al. Cardiac extracellular matrix hydrogel together with or without inducer cocktail improves human adipose tissuederived stem cells differentiation into cardiomyocyte-like cells. Biochem Biophys Res Commun 2018;502:215-25.

6. Piryaei A, Soleimani M, Heidari MH, et al. Ultrastructural maturation of human bone marrow mesenchymal stem cells-derived cardiomyocytes under alternative induction of 5-azacytidine. Cell Biol Int 2015;39:519-30.

7. Laflamme MA, Chen KY, Naumova AV, et al.

Cardiomyocytes derived from human embryonic stem cells in pro-survival factors enhance function of infarcted rat hearts. Nat Biotechnol 2007;25:1015-24.

8. Zamilpa R, Navarro MM, Flores I, et al. Stem cell mechanisms during left ventricular remodeling postmyocardial infarction: Repair and regeneration. World J Cardiol 2014;6:610-20.

9. Sanganalmath SK, Bolli R. Cell therapy for heart failure: a comprehensive overview of experimental and clinical studies, current challenges, and future directions. Circ Res 2013;113:810-34.

10. Kakkar A, Nandy SB, Gupta S, et al. Adipose tissue derived mesenchymal stem cells are better respondents to TGF $\beta 1$ for in vitro generation of cardiomyocyte-like cells. Mol Cell Biochem 2019;460:53-66.

11. Strioga M, Viswanathan S, Darinskas A, et al. Same or not the same? Comparison of adipose tissue-derived versus bone marrow-derived mesenchymal stem and stromal cells. Stem Cells Dev 2012;21:2724-52.

12. Joo HJ, Kim JH, Hong SJ. Adipose Tissue-Derived Stem Cells for Myocardial Regeneration. Korean Circ J 2017;47:151-9.

13. Suzuki E, Fujita D, Takahashi M, et al. Adipose tissuederived stem cells as a therapeutic tool for cardiovascular disease. World J Cardiol 2015;7:454-65.

14. Gutkowska J, Jankowski M, Antunes-Rodrigues J. The role of oxytocin in cardiovascular regulation. Braz J Med Biol Res 2014;47:206-14.

15. Ybarra N, Vincent P, Smith LC, et al. Oxytocin improves the expression of cardiac specific markers in porcine bone marrow stem cells differentiation. Res Vet Sci 2015;98:42-50.

16. Kakkar A, Mohanty S, Bhargava B, et al. Role of human cardiac biopsy derived conditioned media in modulating 
bone marrow derived mesenchymal stem cells toward cardiomyocyte-like cells. J Pract Cardiovasc Sci 2015;1:150-5.

17. Yang Q, Wu F, Wang F, et al. Impact of DNA methyltransferase inhibitor 5-azacytidine on cardiac development of zebrafish in vivo and cardiomyocyte proliferation, apoptosis, and the homeostasis of gene expression in vitro. J Cell Biochem 2019;120:17459-71.

18. Gilsbach R, Preissl S, Grüning BA, et al. Dynamic DNA methylation orchestrates cardiomyocyte development, maturation and disease. Nat Commun 2014;5:5288.

19. Sharaf Eldin HEM, Ibrahim MAA, Mousa AMI, et al. Cardiogenic Differentiation of Murine Bone MarrowDerived Mesenchymal Stem Cells by 5-Azacytidine: A Follow-up In vitro Study. J Microsc Ultrastruct 2019;7:185-93.

20. Griffin MF, Naderi N, Kalaskar DM, et al. Argon plasma surface modification promotes the therapeutic angiogenesis and tissue formation of tissue-engineered scaffolds in vivo by adipose-derived stem cells. Stem Cell Res Ther 2019;10:110.

21. Bagheri-Hosseinabadi Z, Mesbah-Namin SA, Salehinejad $\mathrm{P}$, et al. Fibrin scaffold could promote survival of the human adipose-derived stem cells during differentiation into cardiomyocyte-like cells. Cell Tissue Res 2018;372:571-89.

22. Seyedi F, Farsinejad A, Nematollahi-Mahani SN. Fibrin scaffold enhances function of insulin producing cells differentiated from human umbilical cord matrix-derived stem cells. Tissue Cell 2017;49:227-32.

23. Rodrigo SF, van Ramshorst J, Hoogslag GE, et al.

doi: 10.21037/sci-2020-007

Cite this article as: Saheli M, Pirhajati Mahabadi V, MesbahNamin SA, Seifalian A, Bagheri-Hosseinabadi Z. DNA methyltransferase inhibitor 5-azacytidine in high dose promotes ultrastructural maturation of cardiomyocyte. Stem Cell Investig 2020;7:22.
Intramyocardial injection of autologous bone marrowderived ex vivo expanded mesenchymal stem cells in acute myocardial infarction patients is feasible and safe up to 5 years of follow-up. J Cardiovasc Transl Res 2013;6:816-25.

24. Mohyeddin-Bonab M, Mohamad-Hassani MR, Alimoghaddam K, et al. Autologous in vitro expanded mesenchymal stem cell therapy for human old myocardial infarction. Arch Iran Med 2007;10:467-73. Erratum in: Arch Iran Med. 2008 Mar;11(2):241. al-Mohamad, Mahmood Ghasemi [corrected to Alemohammad, Mahmood Gholan].

25. Bacakova L, Zarubova J, Travnickova M, et al. Stem cells: their source, potency and use in regenerative therapies with focus on adipose-derived stem cells - a review. Biotechnol Adv 2018;36:1111-26.

26. Markmee R, Aungsuchawan S, Pothacharoen P, et al. Effect of ascorbic acid on differentiation of human amniotic fluid mesenchymal stem cells into cardiomyocytelike cells. Heliyon 2019;5:e02018.

27. Markmee R, Aungsuchawan S, Narakornsak S, et al. Differentiation of mesenchymal stem cells from human amniotic fluid to cardiomyocyte-like cells. Mol Med Rep 2017;16:6068-76.

28. Deng F, Lei H, Hu Y, et al. Combination of retinoic acid, dimethyl sulfoxide and 5-azacytidine promotes cardiac differentiation of human fetal liver-derived mesenchymal stem cells. Cell Tissue Bank 2016;17:147-59.

29. Rachel K, Pathak S, Moorthi A, et al. 5-Azacytidine incorporated polycaprolactone-gelatin nanoscaffold as a potential material for cardiomyocyte differentiation. J Biomater Sci Polym Ed 2020;31:123-40. 